\section{REFERENCES}

1 Mokhlesi B, Kryger MH, Grunstein RR. Assessment and management of patients with obesity hypoventilation syndrome. Proc Am Thorac Soc 2008; 5: 218-225.

2 Subramanian S, Strohl KP. A management guideline for obesity-hypoventilation syndromes. Sleep Breath 1999; 3: 131-138.
3 Campo A, Frühbeck G, Zulueta JJ, et al. Hyperleptinaemia, respiratory drive and hypercapnic response in obese patients. Eur Respir J 2007; 30: 223-231.

\title{
Flow-independent nitric oxide parameters in infants with and without recurrent wheeze
}

\section{To the Editors:}

Flow-independent nitric oxide parameters (FIPs) have given an insight into airway physiology and pathology in adults and children [1]. Measurements of fractional exhaled nitric oxide ( FeNO) are sensitive to respiratory symptoms and environmental exposures in infants [2, 3]; therefore, it would be reasonable to hypothesise that FIPs could extend current understanding about airway pathology in early life. Measurements of FeNO at different expiratory flows are needed to estimate FIPs and, given the challenge in measuring FeNO in infants, it is not surprising that the FIP literature in infants is limited to a single study of five healthy individuals [4]. We measured FeNO at 11 and $40 \mathrm{~mL} \cdot \mathrm{s}^{-1}$ in 14 infants with and without recurrent wheeze as part of a larger methodological study [5]. We have reanalysed our data, derived FIPs, and present our results herein.

The present study population included 14 infants, ten of which were males, of whom seven infants had $\geqslant 3$ episodes of wheeze ever and seven were nonwheezing controls. The modified single-breath technique was used, as has been described in detail by our group elsewhere $[5,6]$. Exhaled nitric oxide was measured online using a chemiluminescence analyser (NOA 280; Seivers Instruments Inc., Boulder, CO, USA). The two-point linear method of Silkoff was used to determine the concentration of nitric oxide in the airway wall (Caw,NO; in ppb) and the diffusion capacity of nitric oxide from the airway wall $\left(D a w, N O\right.$; in $\left.\mathrm{nL} \cdot \mathrm{s}^{-1} \cdot \mathrm{ppb}^{-1}\right)$. This method has previously been validated in young infants, in whom an inverse and linear relationship was demonstrated between FENO and three expiratory flows between 15 and $50 \mathrm{~mL} \cdot \mathrm{s}^{-1}$ [4].

The median (range) age of participants was 33 (19-80) weeks, the median (range) height $71(65,80) \mathrm{cm}$ and the median (range) weight $9.3(6.4,15.4) \mathrm{kg}$. Table 1 presents the FENO values at 11 and $40 \mathrm{~mL} \cdot \mathrm{s}^{-1}$. We have previously reported flow dependence of FENO in infants [5]. There were no relationships between FIPs and sex, age, height or weight. The median (range) Caw,NO for wheezers and controls were 79 (19-245) ppb and 37 (14-68) ppb, respectively. The median (range) of Daw,NO for wheezers and controls were 33

\begin{tabular}{|c|c|c|}
\hline \multirow{2}{*}{$\begin{array}{l}\text { Wheeze status in } \\
\text { infancy }\end{array}$} & \multicolumn{2}{|c|}{ Exhaled NO ppb } \\
\hline & At $11 \mathrm{~mL} \cdot \mathrm{s}^{-1}$ & At $40 \mathrm{~mL} \cdot \mathrm{s}^{-1}$ \\
\hline Nonwheezer & 28.00 & 24.43 \\
\hline Nonwheezer & 51.23 & 31.53 \\
\hline Nonwheezer & 28.85 & 23.10 \\
\hline Nonwheezer & 58.00 & 42.05 \\
\hline Nonwheezer & 32.63 & 25.05 \\
\hline Nonwheezer ${ }^{\#}$ & 50.25 & 42.50 \\
\hline Nonwheezer & 11.85 & 8.60 \\
\hline Wheezer & 19.90 & 15.37 \\
\hline Wheezer & 106.97 & 43.00 \\
\hline Wheezer & 59.00 & 35.47 \\
\hline Wheezer & 47.40 & 37.80 \\
\hline Wheezer & 78.50 & 47.45 \\
\hline Wheezer & 57.85 & 26.90 \\
\hline Wheezer\# & 17.80 & 15.75 \\
\hline
\end{tabular}

$(8-212) \mathrm{nL} \cdot \mathrm{s}^{-1} \cdot \mathrm{ppb}^{-1}$ and $85(35-188) \mathrm{nL} \cdot \mathrm{s}^{-1} \cdot \mathrm{ppb}^{-1}$, respectively. Differences in FIPs between the two groups were not significant. Maternal atopy was determined using the skinprick test. Six mothers of controls were atopic and one mother of a wheezing infant was atopic (Chi squared value 6.2; $p=0.013)$. A total of 12 individuals were followed to age 4 yrs; wheeze persisted in five out of the six wheezers, and was not reported in any of the six controls.

This is the first study to report FIPs in infants with a history of wheeze, most of whom had persistent wheeze by age 4 yrs. Given the small numbers of infants studied and the wide range of FIP values measured, our study was underpowered and the lack of a significant difference in FIPs between the groups was expected. 
SILKOFF et al. [7] hypothesised that increased Daw,NO might be an early manifestation of asthma. However, we found no evidence to support this, since the distribution of Daw,NO was similar for both groups. In contrast, the range of $\mathrm{Caw}$,NO values in the wheezers appeared to be higher than in controls. In asthmatics, Daw,NO is elevated compared with controls $[7,8]$ but $\mathrm{Caw}, \mathrm{NO}$ is not [7]. Factors determining Caw,NO and Daw,NO may be different in infants with early asthma symptoms compared with older individuals who have established disease.

Among the control subjects in the present study, values of Daw,NO in controls were higher than reported previously (range 3-37 $\mathrm{nL} \cdot \mathrm{s}^{-1} \cdot \mathrm{ppb}$ [4]) and CawNO values were lower (49$385 \mathrm{ppb}$ [4]). Apparent differences in FIP values between studies are most likely explained by the small numbers of participants in both studies. In addition, the FeNO values at low flows, known to predominantly influence Daw,NO and Caw,NO [1] differed between studies. The majority of mothers of control infants in the present study were atopic and this is relavent since maternal atopy is known to influence nitric oxide in infants [9].

In summary, we report values of flow independent nitric oxide parameters in infants with and without wheeze. These unique data may be of interest to colleagues interested in nitric oxide physiology in healthy and wheezy infants.

\section{S.W. Turner*, P.J. Franklin*, R.C. Mutch* and S.M. Stick*\# *School of Paediatrics and Child Health, University of Western Australia, and "Dept of Respiratory Medicine, Princess Margaret Hospital for Children, Perth, Australia.}

\section{STATEMENT OF INTEREST}

None declared.

\section{REFERENCES}

1 George SC, Hogman M, Permutt S, Silkoff PE. Modeling pulmonary nitric oxide exchange. J Appl Physiol 2004; 96: 831-839.

2 Latzin P, Kuehni CE, Baldwin DN, Roiha HL, Casaulta C, Frey U. Elevated exhaled nitric oxide in newborns of atopic mothers precedes respiratory symptoms. Am J Respir Crit Care Med 2006; 174: 1292-1298.

3 Franklin PJ, Turner S, Mutch R, Stick SM. Parental smoking increases exhaled nitric oxide in young children. Eur Respir J 2006; 28: 730-733.

4 Martinez T, Weist A, Williams T, Clem C, Silkoff P, Tepper RS. Assessment of exhaled nitric oxide kinetics in healthy infants. J Appl Physiol 2003; 94: 2384-2390.

5 Franklin PJ, Turner SW, Mutch R, Stick SM. Comparisons of single breath and tidal breathing exhaled nitric oxide levels in infants. Eur Respir J 2004; 23: 369-372.

6 Wildhaber JH, Hall GL, Stick SM. Measurements of exhaled nitric oxide with the single-breath technique and positive expiratory pressure in infants. Am J Respir Crit Care Med 1999; 159: 74-78.

7 Silkoff PE, Sylvester JT, Zamel N, Permutt S. Airway nitric oxide diffusion in asthma: Role in pulmonary function and bronchial responsiveness. Am J Respir Crit Care Med 2000; 161: 1218-1228.

8 Pedroletti C, Hogman M, Merilainen P, Nordvall LS, Hedlin G, Alving K. Nitric oxide airway diffusing capacity and mucosal concentration in asthmatic schoolchildren. Pediatr Res 2003; 54: 496-501.

9 Frey U, Kuehni C, Roiha $\mathrm{H}$, et al. Maternal atopic disease modifies effects of prenatal risk factors on exhaled nitric oxide in infants. Am J Respir Crit Care Med 2004; 170: 260-265.

\section{Vitamins as asthmagens in the workplace}

\section{To the Editors:}

The cross-sectional study by SRIPAIBOONKIJ et al [1] on 167 milk powder factory workers from four factories in Thailand reported an increased risk of developing work related symptoms compared with office workers. Milk protein allergy as a cause of occupational asthma is well recognised. In addition, many of the studied workers were exposed to the vitamin mixtures used to fortify milk powder. Workers exposed to vitamins had poorer lung function, with significant reductions in forced vital capacity, and an increased risk of nasal, skin and eye symptoms. Breathlessness and nasal symptoms were increased in packing workers, who were also exposed to vitamins in their work. SRIPAIBOONKIJ et al [1] suggest that the skin symptoms were probably related to natural rubber latex from the factory workers' gloves.

Vitamins are chemically unrelated organic compounds that the body cannot synthesise in sufficient quantities on its own (with the exception of vitamin D), but are essential in small amounts to maintain a normal metabolism and good health. DROUGHT et al. [2] have previously reported occupational asthma caused by thiamine (vitamin $\mathrm{B}_{1}$ ) in workers in a cereal factory, confirmed with specific bronchial provocation tests. Using the quantitative structure-activity relationship (QSAR) model linking chemical structure and their occupational asthma hazard [3], the thiamine molecule has been shown to have a high risk of being a chemical respiratory sensitiser with a hazard index of 0.95 [4].

We used the chemical asthma hazard assessment programme based on the above model to study the common vitamin compounds. The asthma hazard index of a chemical is expressed as a value $0-1$, with 1 indicating definite asthmagenic potential.

Table 1 shows that vitamins $A, D, B_{1}, B_{2}, B_{3}, B_{5}$, biotin and folic acid molecules carry a high probability of causing respiratory sensitisation. Folic acid, which is one of the commonest fortifying agents, has the greatest hazard index of 1 . When the vitamins tested are in the salt form (e.g. pyridoxine hydrochloride), the 